\title{
Survey on Indigenous Protozoa in Effluent Treatment Plant of a Textile Dyeing Industry
}

\author{
Hassan M.M, Alam M.Z and Anwar M.N \\ Microbiology Research Laboratory, Department of Microbiology, University of Chittagong, Chittagong 4331, Bangladesh
}

\begin{abstract}
Effluents from textile dyeing industry are so toxic that it threatens the environment in various ways. Hence, it should be treated before discharge. Biotreatment is the most promising approach for the remediation of toxic industrial effluent where microorganisms breakdown the dye molecule into its nontoxic basic elements. In effluent treatment plants (ETP), protozoa accelerate dye degradation process by stimulating the growth of acting bacteria and also play a key role in clarification of the secondary effluent through engulfment of excess bacteria. However, only a few types of protozoa can survive and thrive on this toxic environment. This study deals with the identification and survey of the protozoa present in the effluent treatment plant of a dyeing industry. Collected samples were stained with Leishman reagent and observed under microscope. A total of 10 protozoa were observed and 6 of them were identified up to genus viz. Paramecium, Nassula, Opercularium, Stylonychia, Telotrochidium, Trachelomonas on the basis of their morphological and structural arrangements observed under microscope. Hence, this study reveals that some protozoa can thrive in toxic dyeing effluent and play an important role in maintaining the sustainability of an effluent treatment plant (ETP).
\end{abstract}

Keywords: Dyeing effluent, ETP, Protozoa

\section{Introduction}

Water pollution is one of the most concerned environmental pollution worldwide where dye based industrial effluent play the major role ${ }^{1}$ and regrettably about $10-15 \%$ of the wide range of annual dyestuffs ultimately find its way to the water as waste due to insufficient processing ${ }^{2-4}$. Besides, many dyes are thought to be toxic, carcinogenic or derivatives of known carcinogen like benzidine ${ }^{4-5}$. Bioremediation is the most promising way to solve all the dye effluent based problems because microorganisms can utilize a diverse waste water constituents to get energy and building block for their metabolism and cell synthesis respectively ${ }^{6}$. An efficient wastewater treatment plant is not only rely on the bacterial population but also to that of protozoa ${ }^{7}$ and a high protozoa density of more than $10^{3} / \mathrm{mL}$ with dominancy of crawling and sessile forms is also important ${ }^{8}$. Protozoa are also an indicator of activated sludge condition ${ }^{9}$. A poor activated sludge condition is indicated by the presence of abundant flagellates and rhizopods with less ciliates whereas good sludge condition is one that is dominated by restricted species of ciliates where flagellates and rhizopods are $\operatorname{rare}^{10}$. Among the three categories (Flagellates, Sarcodines and ciliates) of protozoa, ciliates are predominant in waste water treatment ${ }^{11}$. By stimulating bacterial growth, engulfing excess bacteria and promoting flocculation, protozoa maintain the balance of the system ${ }^{12}$. Moreover, consumption of free bacteria reduces the turbidity of the effluent and also its BOD and suspended matter content ${ }^{13}$. Thus, this study aims to the survey of protozoa present in the ETP of our concerned textile industry.

\section{Materials and Methods}

Sample collection

A total of 10 samples were collected randomly from different zones of the ETP oxidation tank of Qualitex Industries (BD) Ltd., Export processing zone, Chittagong, Bangladesh. After collection, time, date, colour, temperature and $\mathrm{pH}$ of the samples were recorded immediately and brought to the laboratory by maintaining aerobic condition.

\section{Staining of sample}

Staining was done by taking $5 \mathrm{ml}$ of sample in a test tube half of which was filled with same amount of normal saline $(0.85 \% \mathrm{NaCl})$. A few drops of leishman stain $(0.15 \mathrm{~g}$ in $100 \mathrm{ml}$ methanol) was then added in the same test tube after mixing the sample with normal saline. Tubes were kept undisturbed for $20-30$ minutes for the dyes to be taken up by the protozoa.

\section{Observation and quantification}

A few drop of prepared sample from the test tube was taken on a clean glass slide using a dropper. Slides were then observed under light microscope at various magnifications (10X, 40X) after placing a cover slip on it. Morphological properties and structural 
arrangements of protozoa observed live under microscope, images captured by digital camera and compared with the standard description given in "Invertebrates: Protozoa through ctenophora"14 and various previous studies 9,10 on structural properties of protozoa. Finally, percentage of flagellates and ciliates were determined by enumerating observed protozoa.

\section{Results and Discussions}

Presence of an appreciable amount of protozoa is important factor of an efficient ETP and thus this study surveyed the presence of protozoa in our concerned ETP. Physicochemical analysis of the sample was done immediately after collection. Colour of all collected samples were found ash where the temperature ranges from 26 to 28 and $\mathrm{pH} 7.3$ to 7.7 .

Table 1. Physicochemical properties of the samples

\begin{tabular}{lccc}
\hline Sample Number & Colour & $\mathrm{pH}$ & Temperature $\left({ }^{\circ} \mathrm{C}\right)$ \\
\hline OT1 & Ash & 7.5 & 27 \\
OT2 & Ash & 7.4 & 26 \\
OT3 & Ash & 7.5 & 26 \\
OT4 & Ash & 7.3 & 28 \\
OT5 & Ash & 7.4 & 28 \\
OT6 & Ash & 7.7 & 28 \\
OT7 & Ash & 7.6 & 27 \\
OT8 & Ash & 7.5 & 26 \\
OT9 & Ash & 7.6 & 28 \\
OT10 & Ash & 7.5 & 27 \\
\hline
\end{tabular}

Identification of the protozoa was done by analyzing the images taken under light microscope and comparing them with the standard descriptions ${ }^{9-10,14}$. A total of 10 different protozoa were observed in our concerned effluent treatment plant (ETP). Among them 6 were identified after observing following characteristics while the remaining 4 are yet to be identified.

Stylonychia, genus of ciliate under the order Hypotrichida was abandoned in all samples and easily detectable due to their rapid movement throughout the environment. Its shape is oval from the top view and typical fused tuft of cilia called cirri on the ventral (underside) surface which they use like legs in crawling, was also clearly visible. It is also notable that cirri present at the posterior end are long while the shorts are at the anterior ${ }^{14}$ (Figure 1).

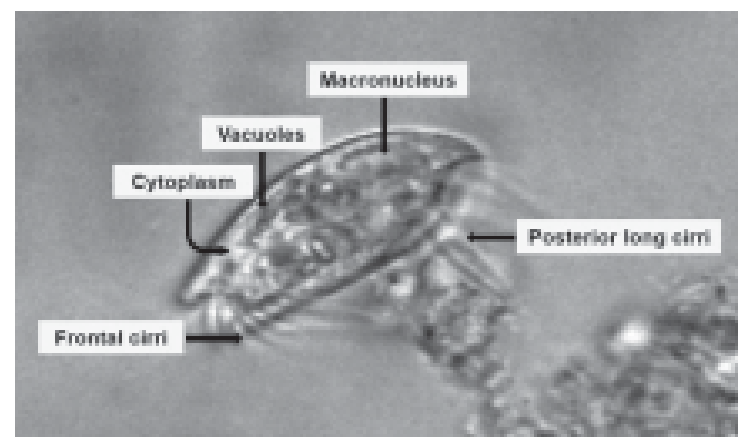

Figure 1. Crawling of Stylonychia sp. (40X view)
The most common protozoa found in activated sludge called Paramecium sp were present at high numbers in all samples. They were covered with minute hair like extensions called cilia which play important role during locomotion and feeding. A stiff membrane called Pellicle gives its definite shape. Buccal cavity was also clearly visible through which engulfed bacteria pass into the gullet. The large nucleus called macronucleus important for the survival of Paramecium also distinguished easily. Food vacuoles, constricted structure of esophageal sac evenly distributed through the cytoplasm ${ }^{14-16}$ (Figure 2).

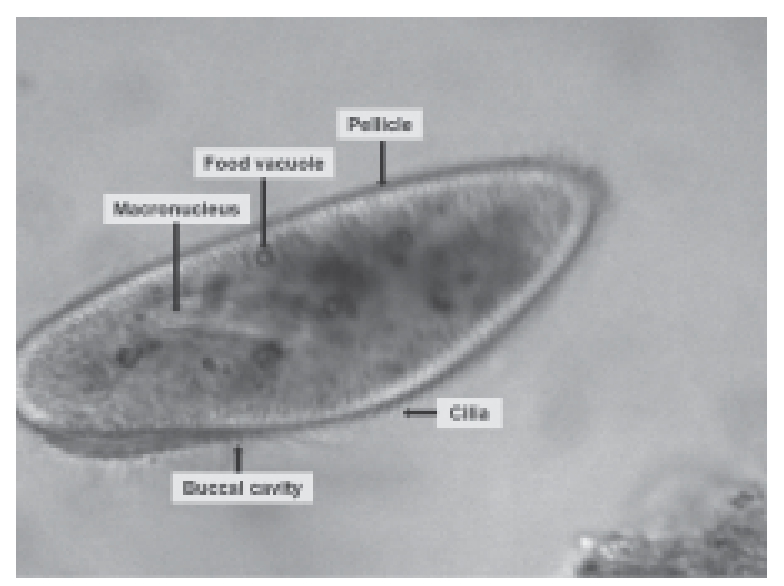

Figure 2. Microscopic view of Paramecium sp. (40X view)

Nassula belonging to the class Nassophorea easily distinguished by its feeding apparatus called Nasse or cyrtos which are made up of some closely packed microtubules. Their number is not so abandoned. Numerous contractile vacuoles were also visible throughout the cell ${ }^{14}$ (Figure 3).

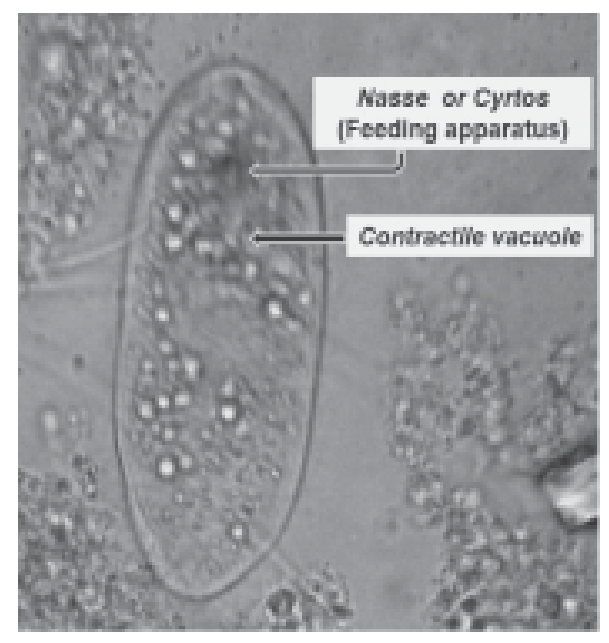

Figure 3. Microscopic view of Nassula sp. (40X view)

Telotrochidium which are motile peritricha with permanent posterior gridles was observed to swim about rapidly by their posterior circlet with the posterior end in advance. Aboral cilliary wreath, adoral cilliary spiral and macronucleus were also clearly visible under microscope ${ }^{14,17}$ (Figure 4). 


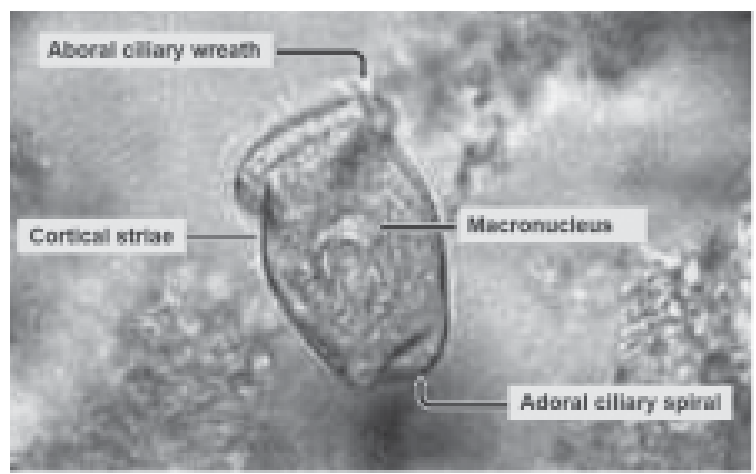

Figure 4. Swimming of Telotrochidium (40X view)

Trachelomonas are small euglenoid flagellate. In this experiment, we observed a free moving Trachelomonas sp. which usually encapsed within a rigid lorica ${ }^{14}$ (Figure 5).

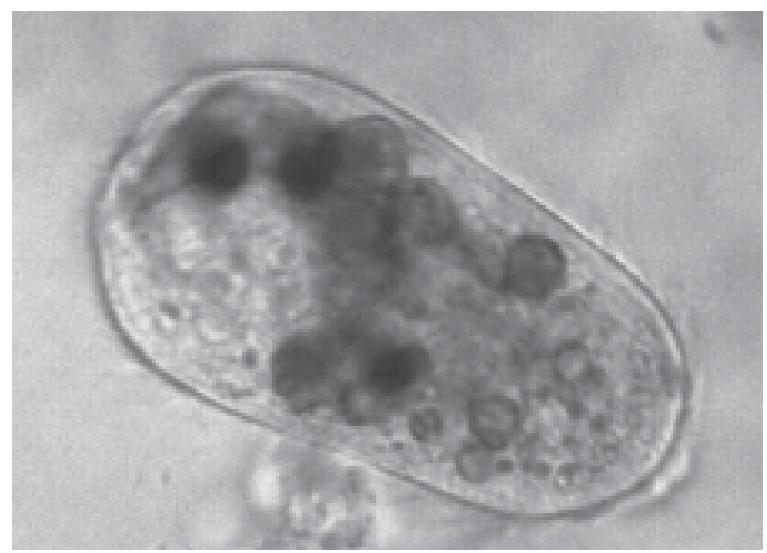

Figure 5. Free cell of Trachelomonas (40X view)

A sessile genus Opercularia was observed fastening with some waste materials through their stalks. Buccal area with a disc is clearly separated from the peristomial boarder by a deep incision. The disc is small and oblique ${ }^{14,18-19}$ (Figure 6).

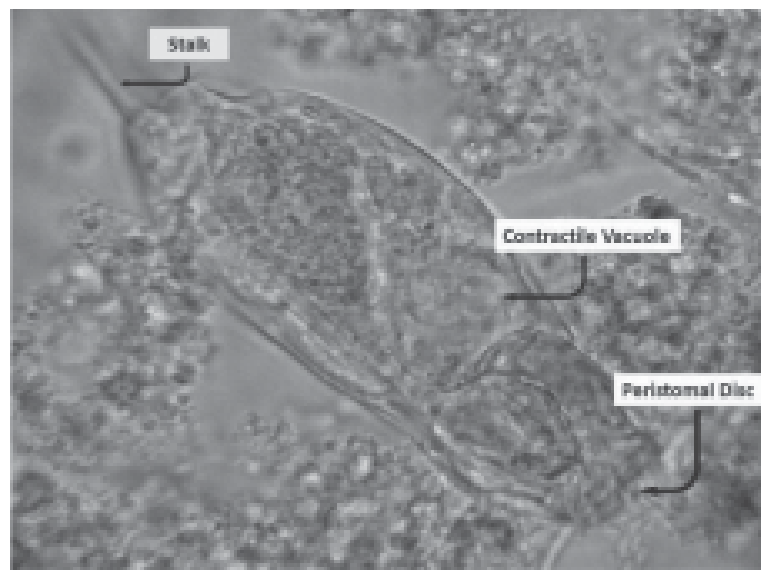

Figure 6. A single Opercularia sp. (40X view)
Rest of the protozoa (POT 7, POT 8, POT 9 and POT 10) which are yet to be identified are given in the figure 7, 8, 9 and 10.

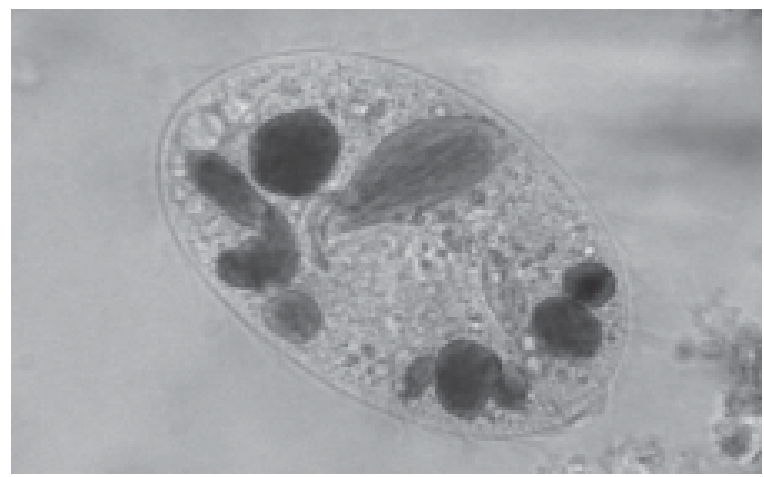

Figure 7. Unidentified protozoa (POT 7)

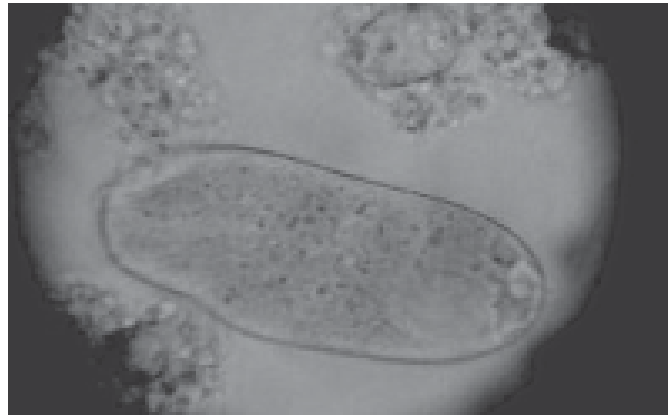

Figure 8. Unidentified protozoa (POT 8)

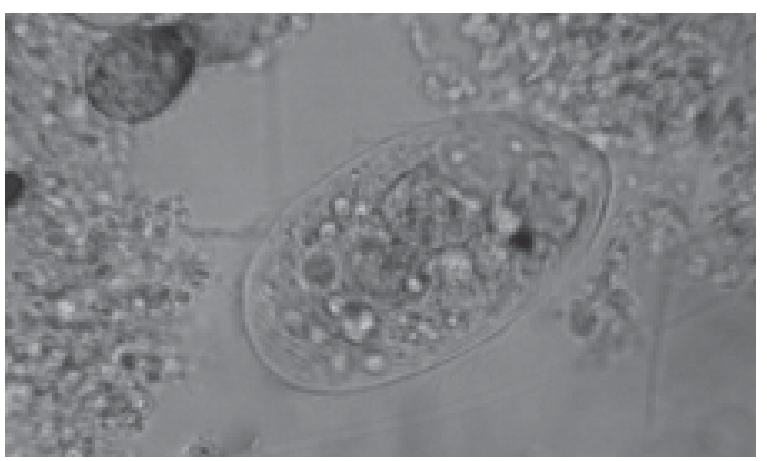

Figure 9. Unidentified protozoa (POT 9)

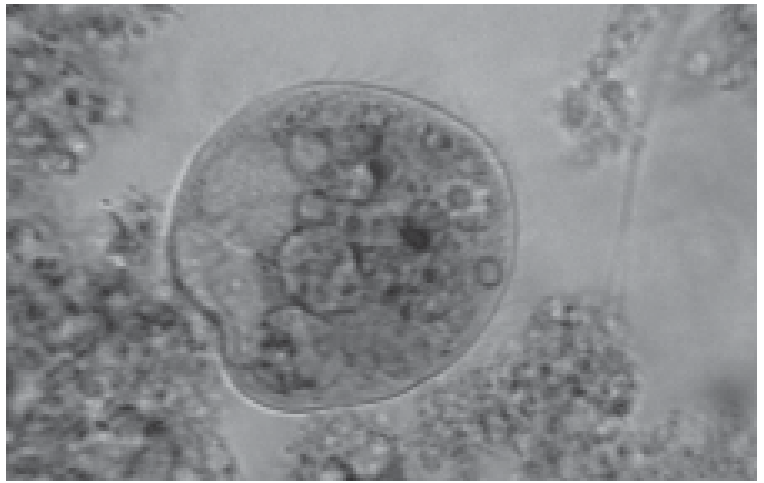

Figure 10. Unidentified protozoa (POT 10) 
After analyzing all the images and compare them with standard descriptions we could determine that among 10 different genus of protozoa 9 of them are ciliates and one (Trachelomonas) is flagellate. So, the percentage of ciliates and flagellates is 90 and 10 respectively (Table 2 ).

Table 2. Quantitative study of the protozoa from oxidation tank sample

\begin{tabular}{lc}
\hline Type of protozoa & Percentage (\%) \\
\hline Ciliates & 90 \\
Flagellates & 10 \\
\hline
\end{tabular}

According to a previous study ${ }^{20}$, it is evident that the physicochemical parameters ( $\mathrm{pH}$ and temperature) of all the collected samples provide a wonderful breeding environment for protozoa and thus significant number of protozoa are reported to harbor here. Among them, dominating number of ciliates (90\%) represents a satisfactory sludge condition since some previous analysis $^{10-11}$ on efficient waste water treatment plant reported the presence of significant numbers of ciliates compared with flagellates.

\section{Conclusion}

The sustainability of an ETP is mainly depends upon the quantity of the ciliate population present in activated sludge, serving ciliates as the crucial agent for ETP diagnosis. From the percent analysis and identification of some protozoa groups' i. e. flagellate, ciliate, sarcodine, metazoan and types of ciliates i. e. carnivorous, crawling, free swimming and sessile, of our concerned ETP, it is quite evident that the plant is in an ideal state of operation. Here, presence of $90 \%$ ciliates among total protozoan population indicating high efficiency of the activated sludge of our concerned ETP.

\section{References}

1. Cripps C, Bumpus AJ, Aust SD. 1990. Biodegradation of azo and heterocyclic dyes by Phanerochaete chrososporium. Applied Environ. Microbiol. 56: 1114 - 1118.

2. Meyer U. 1981. Microbial Degradation of Xenobiotics and Recalcitrant Compounds. Leisinger T, Cook AM, Nuesch J, Hutter R (eds), pp. 371 - 385. Academic Press, London.

3. Zollinger H.1987. Colour chemistry - syntheses. Properties and applications of organic dyes and pigments. VCH publishers, New York.
4. Kariminiaae-Hamedaani HR, Sakurai A, Sakakibara M. 2007. Decolorization of synthetic dyes by a new manganese peroxidase producing white rot fungus. Dyes Pigments. 72: 157-162.

5. Novotny C, Dias N, Kapanen A, Malachova K, Vandrovcova M, Itavaara M, Lima N. 2006. Comparative use of bacterial, algal and protozoan tests to study toxicity of azo and anthraquinone dyes. Chemosphere. 63: 1436-1442.

6. Schultz TE. 2005. Biological Wastewater Treatment. Chem. Eng. Mag. 112: 44-49.

7. Nicolau A, Lima N, Mota N, Madoni P. 1997. Os Protozoários como Indicadores da Qualidade das Lamas Activadas. Boletim de Biotecnologia. 56:14-19.

8. Madoni P. 1994. A sludge biotic index (SBI) for the evaluation of the biological performance of activated-sludge plants based on the microfauna analysis. Water Research. 28: 67-75.

9. Curds CR, Cockburn A. 1970a. "Protozoa in biological sewagetreatment processes- A Survey of the protozoan fauna of British percolating filters and activated-sludge plants." Water Research. 4: 225-236.

10. Baines S, Hawkes HA, Hewitt CH and Jenkins SH. 1953. Protozoa as indicators in activated sludge treatment sewage and industrial wastes. Sewage and Industrial Wastes. 25(9): 1023-1033.

11. Richard M. 1989. Activated Sludge Microbiology. The Water Pollution Control Federation: Alexandria.

12. Gerardi MH, Horsfall FL. 1995. Wastewater Biology: The Microlife, 2nd edition, pp. 71- 78. A Special Publication, Water Environment Federation, Alexandria, Virginie.

13. Curds CR, Cockburn A, Vandike JM. 1968. An Experimental Study of the Role of the Ciliated Protozoa in the Activated-Sludge Process. Wat. Pollut. Control. 67: 312-329.

14. Hyman LH. 1960. Invertibrates: Protozoa through Ctenophora, $1^{\text {st }}$ ed., pp 116 - 200. American Museum of natural History, New York.

15. Mast SO. 1947. The Food-Vacuole in Paramecium. Biol. Bull. 92(1): 31-72.

16. Samworth M. 1999. "Paramecium". Microscopy UK. Available at: http://www.microscopyuk.org.uk/mag/indexmag.html?http:// www.microscopy-uk.org.uk/mag/articles/param1.html, Accessed: $1^{\text {st }}$ April, 2013.

17. Mercedes MC, Almudena G, Elisa B, Patricia D, Gianfranco N, Wilhelm F. 2007. Classification of the peritrich ciliate Opisthonecta matiensis (Martín-Cereceda et al. 1999) as Telotrochidium matiense nov. comb., based on new observations and SSU rDNA phylogeny. European Journal of protistology. 43(4): 265-279.

18. Bick H. 1972. Ciliated Protozoa. An illustrated guide to the species used as biological indicators in freshwater biology. pp. 198. World Health Organization, Geneva.

19. Corliss JO. 1979. The Ciliated Protozoa: Characterization, Classification and Guide to the Literature, Second Edition. pp. 455. Pergamon Press, Oxford.

20. McKinney RE. 2004. Environmental Pollution Control Microbiology: A Fifty-Year Perspective, CRC Press, USA, ISBN 9780824754938. 